\title{
Arielle Meyer, Le Spectacle du secret
}

\section{Philippe Andrès}

\section{(2) OpenEdition}

\section{Journals}

\section{Édition électronique}

URL : http://journals.openedition.org/studifrancesi/36297

DOI : $10.4000 /$ studifrancesi.36297

ISSN : 2427-5856

\section{Éditeur}

Rosenberg \& Sellier

\section{Édition imprimée}

Date de publication : 1 juillet 2005

Pagination : 175-176

ISSN : 0039-2944

\section{Référence électronique}

Philippe Andrès, "Arielle Meyer, Le Spectacle du secret », Studi Francesi [En ligne], 145 (XLIX | I) | 2005,

mis en ligne le 30 novembre 2015, consulté le 20 avril 2021. URL : http://journals.openedition.org/

studifrancesi/36297; DOI : https://doi.org/10.4000/studifrancesi.36297

\section{Ce document a été généré automatiquement le 20 avril 2021.}

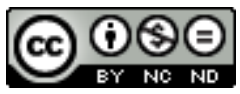

Studi Francesi è distribuita con Licenza Creative Commons Attribuzione - Non commerciale - Non opere derivate 4.0 Internazionale. 


\title{
Arielle Meyer, Le Spectacle du secret
}

\author{
Philippe Andrès
}

\section{RÉFÉRENCE}

ARIELLE MEYER, Le Spectacle du secret, Genève, Droz, 2003 («Histoire des idées et critique

littéraire»), pp. 261.

1 L'ouvrage se propose de cerner les «contours imprécis» du secret, de décrypter les rouages du mécanisme de son fonctionnement en littérature. Il est cependant dommage que le genre poétique soit d'emblée exclu. Après avoir défini la différence entre «énigme» et «mystère», Arielle Meyer annonce sa thèse: le secret ne relève pas d'une mise à l'écart, mais d'une "confusion qui nécessite le recours à l'illusion», justifiant ainsi une étude centrée essentiellement sur le genre théâtral et sur le thème du secret lié au désir. La démarche de l'auteur relève d'une critique thématique, sans doute dépassée, liant l'étude des formes et des significations.

Dans la première partie («Le fonctionnement du secret», pp. 23-66), A. Meyer propose une terminologie théorique afin d'analyser la conception dynamique du secret autour de la «règle de substitution»: elle s'intéresse à la notion «d'intersubjectivité», met à nu «les modalités du processus de substitution» dans le jeu complexe entre «mensonge» et «secret», souligne l'importance $d u$ «double message», révèle la dynamique entre «tension et substitution», pour enfin tenter une définition du «paradoxe du secret» qui «consiste à montrer qu'on cache». À partir d'une fine analyse du théâtre de Marivaux, elle montre le fonctionnement de «l'ostentatoire», véritable jouissance consistant à exhiber le secret devant ses destinataires.

3 La deuxième partie ( «Jeu et secret», pp. 67-132) est consacrée à une analyse du baroque. Mademoiselle de Maupin est étudiée pour son lien étroit entre le ludique et le pervers, au coeur même d'une orientation fétichiste, où le salon mondain incarne le lieu de la théâtralité: Meyer analyse particulièrement le moment où Madeleine revêt le costume masculin pour se métamorphoser en Théodore de Séranne, épisode où Gautier stigmatise «séparation et révélation», avant de conclure sur «cette descente dans les 
abîmes de la réflexivité». Puis s'engage une réflexion théorique sur «le lien apparemment contre nature entre le secret et l'illusion» en une réflexion sur la théâtralité du XVIII ${ }^{\mathrm{e}}$ siècle, à partir d'une fine analyse de Comme il vous plaira, pièce emblématique de Shakespeare que Gautier met en abyme dans son roman. L'auteur analyse rapidement l'intimité de Marivaux pour revenir au "syncrétisme de Gautier» dans une interrogation intéressante sur le texte-source du Roman comique de Scarron. Puis elle s'interroge sur les jeux obscurs liant Armance à Olivier ou le Secret de la duchesse de Duras, cerne la dialectique de «l'encodage et du déchiffrement» et conclut sur un «dénouement impossible» du roman stendhalien, véritablement aporétique.

4 La troisième partie («Mystère et secret», pp. 133-234) cherche à cerner chez Barbey d'Aurevilly les liens entre crime, sexualité et secret, dans une perspective psychanalytique. Les Diaboliques présentent une fascination pour ce qui est de l'ordre du caché, notamment par l'omniprésence du motif de la disparition, si bien que le secret se situe, de façon rhétorique, à l'origine du récit et que le romancier doit le capter. Parfois, le récit reste lacunaire comme dans Le Dessous des cartes d'une partie de whist. Le théâtre de la cruauté offert par Le Bonheur dans le crime offre un va-et-vient de la fiction et de la réalité entre dramatisation et narrativisation. Ainsi, Barbey «opère un travail de sape du projet réaliste par le biais de la logique du secret», «désintégr[ant]» donc le réalisme et s'opposant à Zola, puisque le père du naturalisme «ne fait que montrer qu'il montre»: le débat se situe au coeur même d'une «esthétique du dévoilement, prenant appui sur la description». Le romancier naturaliste développe paradoxalement une métaphore picturale et chirurgicale, à la recherche simultanément de la Beauté et de la Vérité objective. Les notes du dossier préparatoire de La Bête humaine témoignent de cette interrogation sur la notion de «mystère».

Une ultime synthèse propose une brève étude de Sarrasine de Balzac, couronnant un ouvrage sérieux qui a le souci de faire avancer la problématique du secret dans son rapport au littéraire, en recourant essentiellement et systématiquement à l'outil psychanalytique. 